\title{
PENGEMBANGAN SISTEM MEKANIK PENGATUR ELEVASI TABUNG PESAWAT SINAR-X LORAD LPX 200
}

\author{
Suroso, Rully Bachtiar, Bangun Pribadi \\ Sekolah Tinggi Teknologi Nuklir- BATAN \\ Jl. Babarsari PO Box 6101, YKBB, Yogyakarta 55283 \\ Email: surosohadi09@gmail.com
}

\begin{abstract}
ABSTRAK
PENGEMBANGAN SISTEM MEKANIK PENGATUR ELEVASI TABUNG PESAWAT SINAR-X LORAD LPX 200. Telah dilakukan pengembangan sistem mekanik yang bertujuan untuk menggerakkan tabung pesawat sinar-X LORAD LPX-200 agar diperoleh pengaturan elevasi tabung yang tepat. Pengembangan sistem mekanik dirancang menggunakan rangkaian roda gigi atau gear reduction yang digerakkan oleh motor, untuk mendapatkan konversi gerak rotasi menjadi gerak linier. Perhitungan dilakukan terhadap pemilihan komponen, ukuran roda gigi, agar mampu menggerakkan tabung sinar-X. Hasil dari desain didapat torsi untuk mengangkat tabung sinar-X sebesar 4,87 $\mathrm{Nmm}$ dan mampu digunakan untuk mengangkat tabung sinar-X dengan kecepatan gerak naik dan turun sebesar $50 \mathrm{~mm} / \mathrm{detik}$.
\end{abstract}

Kata kunci: pengembangan sistem mekanik, elevasi, sinar-X,

\section{ABSTRACT}

DEVELOPMENT OF MECHANICAL DRIVE SYSTEM FOR ADJUSTING ELEVATING TUBE LORAD LPX $200 X-R A Y$. A mechanical drive system for adjusting the tube of Lorad LPX 200 X-ray machine has been developed in order to obtain the right settings of the elevation. It uses a series of gears or gear reduction which is driven by a motor aiming at the conversion of rotational motion into linear motion. Calculation is performed on the selection of the components, dimension of spur gears, to be able for lifting of the $x$-ray tube. Results showed that the torque to lift the X ray tube was 4,87 Nmm and could be used to lift X-ray tube with $50 \mathrm{~mm} / \mathrm{s}$ velocity of up and down displacement.

Keywords: development of mechanical drive system, elevation, $X$-ray

\section{PENDAHULUAN}

Setiap mesin dirancang dan dibuat untuk memberikan fungsi-fungsi tertentu yang dapat meringankan pekerjaan manusia. Salah satunya adalah pesawat sinar- $X$ yang dapat digunakan dalam berbagai jenis kegiatan, untuk industri, kedokteran, penelitian, dan pelatihan [1].

Pesawat Sinar-X konvensional umumnya mempunyai tiga komponen utama, yaitu tabung sinar- $X$, sumber tegangan tinggi, dan unit kendali [2]. Pada tabung sinar-X pada waktu digunakan diposisikan agar focal spot yang berfungsi sebagai tempat dipancarkannya sinar-X menghadap tepat ke arah benda uji atau objek yang akan disinari. Pengaturan geometri seperti ini dilakukan agar bisa mendapatkan kualitas film hasil radiografi yang baik sesuai persyaratan standar yang berlaku [3].
Untuk mendapatkan geometri seperti yang diinginkan, tabung pesawat sinar-X diberi penopang yang dapat diputar vertikal agar posisi focal spot berada pada sudut yang tepat dan ketinggian window pada tabung sesuai dengan perhitungan Source to Film Distance (SFD). Untuk mempermudah pengaturan tersebut, diperlukan pengembangan alat penopang yang dapat mengatur posisi sudut dan elevasi tabung pesawat sinar- $X$ dengan mudah dan memberikan presisi sudut yang baik.

Pengembangan sistem mekanik pengatur tabung sinar-X diharapkan dapat berhubungan dengan ketepatan sudut dan elevasi focal spot, sehingga akan meningkatkan kinerja dan efisiensi waktu untuk set-up benda kerja dan akhirnya akan mempersingkat waktu untuk menyelesaikan pekerjaan. 
Beberapa hal yang dilakukan sebelumnya untuk mengatur tabung pesawat sinar-X, cara untuk mengatur/melakukan set-up tabung pesawat atau mengatur sudut dan elevasi tabung, diatur secara manual seperti ditunjukkan pada Gambar 1 sehingga perlu dilakukan pengembangan sistem mekanik pengatur tabung sinar-X.

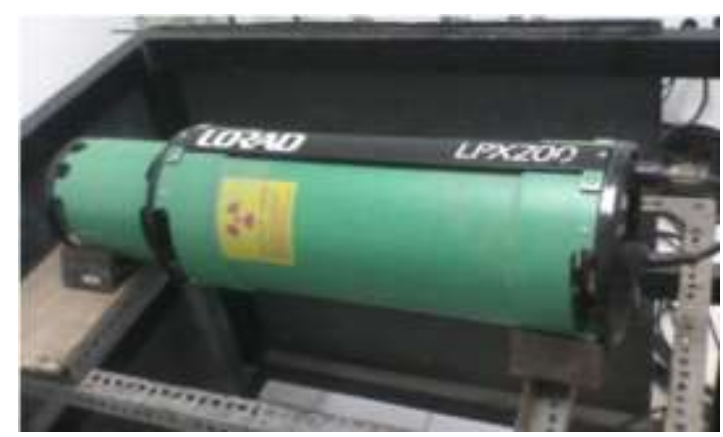

Gambar 1. Tabung Sinar-X Lorad LPX 200 Ditumpu dengan Papan dan Besi Siku

Pemilihan sistem gerak mekanik dengan menggunakan gear reduction bertujuan untuk mendapatkan konversi gerak rotasi dari engkol menjadi gerakan linier dan putaran pada tabung untuk mengarahkan jendela focal spot. Dengan sistem gerak mekanik gear akan kecil kemungkinan terjadi selip, sehingga mampu menahan kapasitas beban dan putaran untuk mengatur tabung [4].

Rancang bangun sistem mekanik pengatur tabung sinar-X Lorad LPX 200 ini bertujuan agar diperoleh pengaturan sudut dan elevasi yang tepat sehingga kualitas film hasil radiografi menjadi baik sesuai persyaratan standar yang berlaku.

\section{PESAWAT SINAR-X}

Pesawat Sinar-X pada dasarnya terdiri dari bagian utama yaitu sumber tegangan tinggi (HV), unit kontrol dan tabung sinar-X. Sumber tegangan tinggi (HV) berfungsi untuk memberi catu tegangan kerja tabung yang diatur oleh unit kontrol sehingga tabung dapat menghasilkan sinar-X. Tabung sinar-X terdiri atas katoda, anoda, dan target yang diselimuti dengan selubung gelas atau bahan lain. Selubung tabung dilindungi dengan rumah tabung yang terbuat dari bahan logam. Di antara selubung dan rumah tabung diberikan cairan isolator untuk menghindari kontak listrik dan juga berfungsi sebagai pendingin [5].
Pada Gambar 2 diperlihatkan pesawat sinar-X LORAD LPX-200 yang dijadikan objek penelitian untuk diatur sudut dan elevasinya. Dimensi masing-masing komponennya dapat dilihat pada Gambar 2.

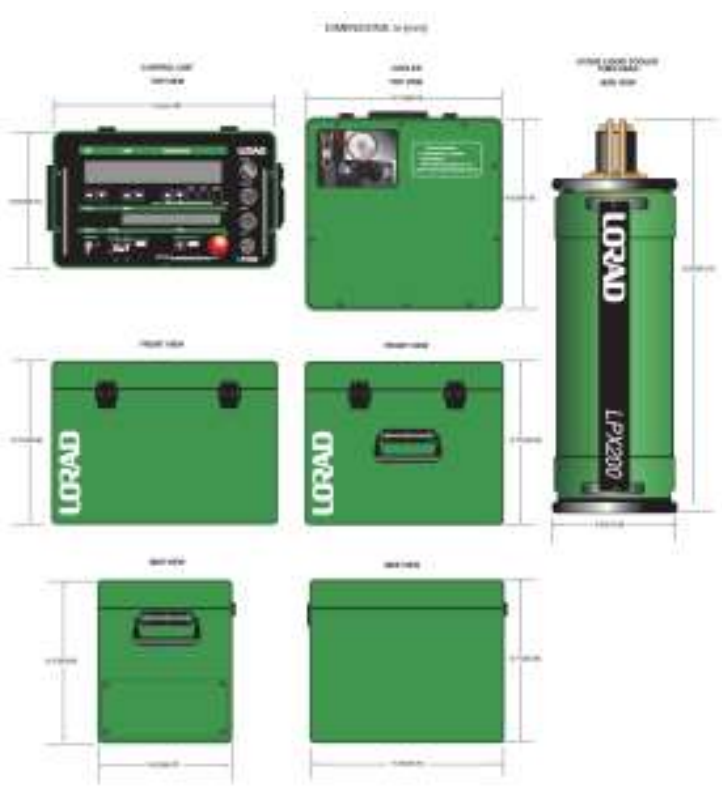

Gambar 2. Dimensi Pesawat Sinar-X LORAD LPX 200 [5]

\section{Trasmisi Mekanik}

Transmisi mekanik adalah salah satu bagian dari sistem pemindah tenaga yang berfungsi untuk mengkonversi gerak, momen dan kecepatan sesuai dengan perencanaan dari perhitungan pembebanan, yang umumnya menggunakan perbandingan roda gigi. Prinsip dasar transmisi adalah bagaimana mengubah kecepatan putaran suatu poros menjadi kecepatan putaran gerak atau putaran yang diinginkan.

Fungsi transmisi adalah untuk mengatur perbedaan putaran antara sumber tenaga dengan putaran poros yang keluar dari transmisi. Pengaturan putaran ini dimaksudkan agar sistem mekanik dapat bergerak sesuai beban dan kecepatan yang diharapkan.

\section{Roda Gigi}

Roda gigi lurus adalah jenis roda gigi yang paling banyak digunakan dan paling umum yang banyak dijumpai, yang biasanya digunakan untuk poros yang sejajar atau paralel. Dibandingkan dengan jenis roda gigi yang lain, roda gigi lurus paling mudah dalam proses pembuatannya (machining) sehingga harganya ekonomis. 
Roda gigi lurus cocok digunakan pada sistem transmisi yang gaya kelilingnya besar, karena tidak menimbulkan gaya aksial $[4,6]$. Pada saat gerakan berputar, roda gigi memindahkan daya pada roda gigi pasangannya ke arah sudut tangensial pada masing-masing pertengahan lingkaran dari pertemuan roda gigi. Bentuk roda gigi lurus bepasangan dengan pinionnya dapat dilihat pada Gambar 3.

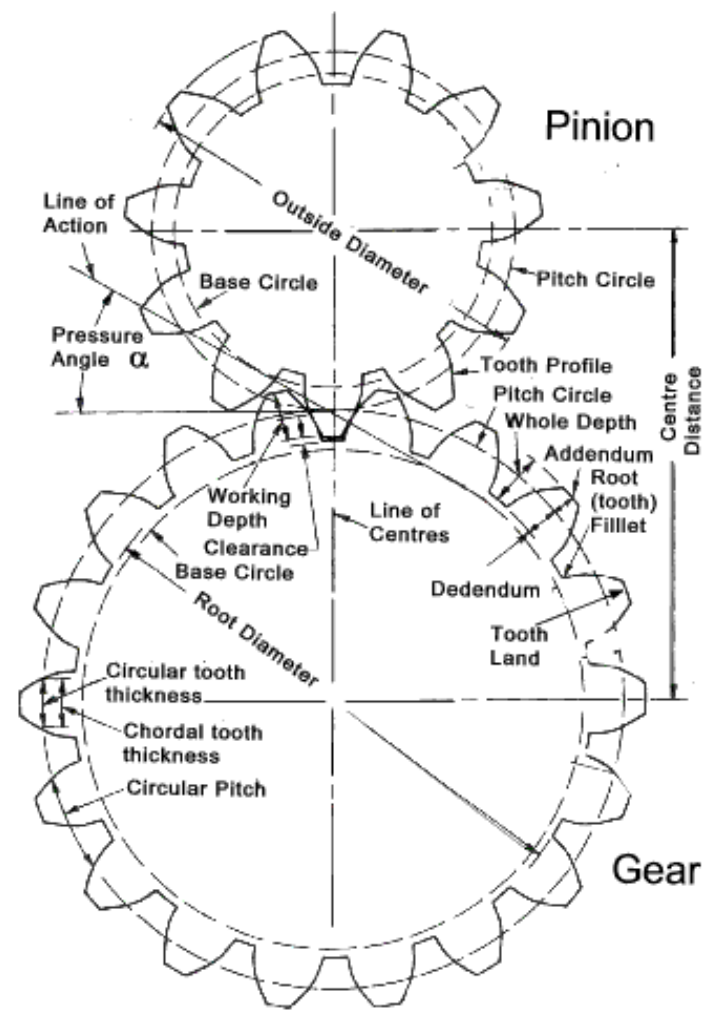

Gambar 3. Roda Gigi Lurus [4]

\section{Perhitungan Reduksi Roda Gigi}

Mekanik penggerak untuk pengangkat beban adalah lead screw dan tabung ulir yang digerakkan oleh roda gigi yang dipasang pada poros seperti Kecepatan angkat yang didinginkan $\mathrm{v}=4 \mathrm{~cm} /$ detik, putaran roda gigi $(\mathrm{n} 2)=\mathrm{v} / \mathrm{S}=40 / 4 \mathrm{rpm}=10 \mathrm{rpm}$. Jumlah gigi yang tersedia pada pinion $\left(Z_{1}\right)$ adalah 15 gigi, sedangkan roda gigi untuk lead screw yang tersedia $\left(\mathrm{Z}_{2}\right)$ adalah 60 gigi. Untuk diameter masing-masing roda gigi yaitu $\mathrm{D}_{1}=45 \mathrm{~mm}$ dan $\mathrm{D}_{2}=180 \mathrm{~mm}$, modul $\mathrm{M}=3$. [7]. Perhitungan daya ditentukan oleh daya yang ditransmisikan, putaran gigi dan diameter gigi.

$\mathrm{N} 75 \mathrm{~kg} \mathrm{~m}) / \mathrm{dtk}=P+\frac{\text { jalan yg dilalui }}{\text { detik }}$.
Gaya yang bekerja pada roda gigi dapat dihitung: Usaha $=$ gerak $\mathrm{x}$ jalan (2), $1 \mathrm{HP}=$ kilogram meter tiap detik.

\section{POROS}

Perhitungan pada poros ditentukan menurut pembebanannya yang dapat diklasifikasikan ke dalam beberapa jenis, yaitu poros transmisi, poros gandar atau as, dan poros spindle (poros mesin) [8]. Poros transmisi adalah bagian mesin yang berputar, biasanya bentuk penampangnya bulat, digunakan untuk memindahkan daya melalui putaran. Daya yang diteruskan melalui roda gigi, kopling, puli sabuk, sproket rantai. Hal yang penting di dalam perhitungan poros. Tabung sinar- $X$ yang akan diatur elevasinya dalam penelitian ini mempunyai berat $60 \mathrm{~kg}$.

Perhitungan untuk mendapatkan ukuran diameter poros $[4,7]$ agar mampu mengangkat beban tabung sinar-X maka perlu dilakukan perhitungan dengan menggunakan Persamaan (2).

$$
\sigma t=\frac{P \cdot K t}{\frac{\pi}{4} \cdot d^{2}}
$$

dengan:

$\sigma \mathrm{t}$ Tegangan tarik yang diizinkan $(\mathrm{kg} / \mathrm{cm} 2)$

$$
\begin{aligned}
& \mathrm{P}: \text { Beban }(\mathrm{kg}) \\
& \mathrm{dk}: \text { Diameter poros }(\mathrm{cm})
\end{aligned}
$$

Kt : Nilai desain awal

Nilai desain awal untuk Kt, dipertimbangkan di sini adalah jenis diskontinuitas geometris yang paling sering ditemukan pada poros (diameter poros) untuk transmisi.

Beban P maksimum yang disarankan dapat dihitung dari Persamaan (3) [8] :

$\mathrm{P} \leq \mathrm{F}_{1} . \mathrm{N}_{\mathrm{t}}$

dengan $\mathrm{F} 1$ adalah bidang dukung poros, sedangkan $\mathrm{Nt}$ adalah tekanan bidang yang diperbolehkan pada poros.

\section{Perhitungan Rangka/Body Mekanik Elevasi}

Perhitungan pada frame body mekanik penumpu tabung sinar-X yaitu tegangan yang bekerja pada body penumpu sinar- $\mathrm{X}$ dapat berupa kombinasi tegangan, bengkok dan geser juga tegangan yang lain.

Body sinar-X dapat ditentukan dengan memperhitungkan beban dari tabung sinar-X. 
Bahan menggunakan AISI 1040 Steel Bar. (Yield Strength Sy = 42000 Psi)[4]:

Adapun untuk menghitung dimensi body sinar-X [10]:

$\sigma=\mathrm{M} / \mathrm{S}$

$\sigma=\sigma \mathrm{d}=\mathrm{Sy} / \mathrm{N}$

dengan :

$$
\begin{aligned}
& \mathrm{S}: \text { Section modulus }=\mathrm{t} . \mathrm{h} 2 / 6 \\
& \mathrm{~h}: 3 \mathrm{t} \\
& \mathrm{N}: \text { desain Factor }
\end{aligned}
$$

Pemilihan motor dan perhitungan torsi motor. Untuk pemilihan motor yang berfungsi sebagai penggerak untuk menaikkan dan menurunkan beban tabung sinar-X dipilih motor stepper [9]. Torsi yang digunakan untuk menggerakkan beban memutar roda gigi dapat dihitung dengan Persamaan 6. Apabila $\tan \lambda=$ $\mathrm{p} / \pi \mathrm{Dp}$ maka didapat persamaan [5]:

$$
T u=\frac{F . D_{\mathbf{P}}}{2}\left[\frac{(\cos \oslash \tan \lambda+f)}{(\cos \oslash-\mathrm{ftan} \lambda)}\right]
$$

dengan:

Tu : Torsi untuk menaikan beban (lb.in)

F : Beban (lb)

Dp: Diameter jarak bagi minimum (inchi)

f : Koefisiean gesekan 0,15

Adapun torsi untuk menurunkan beban dapat dihitung dengan rumus Persamaan (7)[10] yaitu:

$\mathrm{Td}=\frac{\mathrm{F} \cdot \mathrm{D}_{\mathrm{P}}}{2}\left[\frac{(\mathrm{f}-\cos \emptyset \tan \lambda)}{(\cos \emptyset+\mathrm{ftan} \lambda)}\right]$

dengan :

Td : Torsi untuk menurunkan beban (lb.in)

F : Beban (lb)

Dp: Diameter jarak bagi minimum (inci)

F : Koefisien gesekan 0,15

\section{METODE PENELITIAN}

\section{Perhitungan Motor Penggerak}

Kecepatan gerak linier naik dan turun yang dibutuhkan direncanakan $5 \mathrm{~cm} /$ detik. Untuk mengangkat beban tabung sinar-X, motor penggerak sekurang-kurangnya harus memenuhi besaran torsi sesuai dengan perhitungan. Apabila diketahui bahwa $\mathrm{p}=$ 0,125 maka sudut kisarnya yaitu $1=$ tan- 1 $\mathrm{p} / \pi \mathrm{Dp}=\tan -1 \quad 0,125 / 3.14 .0,5408=11,983^{\circ}$. Dengan menggunakan Persamaan (6) maka torsi yang dibutuhkan untuk mengangkat beban dihitung sebagai berikut:
$\mathrm{Tu}=\frac{\mathrm{F} \cdot \mathrm{D}_{\mathrm{P}}}{2}\left[\frac{(\cos \varnothing \tan \lambda+\mathrm{f})}{(\cos \varnothing-\mathrm{ftan} \lambda)}\right]$

Dengan $\cos \emptyset=\cos 14,5^{\circ}=0,986, \tan \lambda=$ $\tan 11,98^{\circ}=0,212^{\circ}$, berat $100 \mathrm{~kg}=220 \mathrm{lb}$, maka:

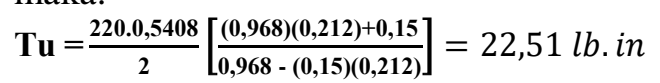

Dengan cara yang sama, menggunakan Persamaan (6) dan (7) dapat dihitung kebutuhan torsi untuk menurunkan beban, didapat $\mathrm{Td}=12,20 \mathrm{lb}$.in.

Dengan torsi untuk menaikan beban yang dibutuhkan sebesar 22,551 lb.in dan torsi untuk menurunkan beban sebesar 12,20 lb.in, maka perlu dipilih motor DC dengan torsi yang mampu mengangkat 25 lb.in (dibulatkan), yaitu untuk menaikan atau menurunkan beban.

Dapat juga dihitung dengan perhitungan $\mathrm{Fa}=$ frictional resistance $=\mu \times$ beban $\times$ gravitasi, dengan $\mu$ adalah rolling frictional coefficient $=0,003$ ), sehingga $\mathrm{Fa}=0,003 \mathrm{x}$ $100 \mathrm{~kg} \times 9,8=2,94$ Newton.[5].

$$
T=\frac{F a .10}{2 \pi .0 .96}=\frac{2,94.10}{2 \pi .0 .96}=4,87 \mathrm{~N} . \mathrm{mm}
$$

\section{Perhitungan Frame Body Tabung Sinar-X}

Ukuran tinggi penumpu tabung sinar-X Lorad LPX 200 ditentukan secara umum SFD mempunyai tinggi $70 \mathrm{~cm}$ sehingga tinggi frame body untuk menggerakkan beban tabung dipilih dari besi/steel bar memiliki panjang minimal $70 \mathrm{~cm}$ dan ukuran luas penampang $\mathrm{h}$ dan $\mathrm{t}$.

Jika bahan dipilih AISI 1040 Steel Bar, maka Yield Strenght Sy $=42000$ psi, design factor $(\mathrm{N})=2$, design stress $\sigma \mathrm{d}=42000 / 2=$ 21000 psi. Didapat ukuran material rectangular bar $6 \times 4 \times 1 / 4$.

\section{Pembuatan Mekanik Penggerak Pesawat Sinar-X.}

Hasil dari perhitungan digunakan untuk menentukan dimensi dan ukuran dalam pembuatan otomasi mekanik penggerak tabung sinar-X Lorad LPX 200, termasuk pemilihan diameter poros, kemudian pemilihan motor, untuk motor dipilih motor DC dengan torsi sebesar $12 \mathrm{Nm}$. Mekanik yang dibangun dipersyaratkan dapat bekerja dengan tepat, akurat, dengan kecepatan waktu (gerak naik turun $60 \mathrm{~cm}-600 \mathrm{~mm})<4$ detik, dapat dioperasikan dengan mengatur ketinggian yang dikehendaki dari layar LCD. Material frame body dibuat dari bahan AISI 1040 steel bar, 
yaitu material rectangular bar $6 \times 4 \times 1 / 4$, yaitu 6 in vertical depth, 4 in width dan $1 / 4$ in wall thickness.

\section{HASIL DAN PEMBAHASAN}

\section{Pengujian Linearitas Gerak Naik dan Turun Tanpa Beban}

Pengujian gerakan ini dilakukan dengan jarak tempuh $500 \mathrm{~mm}$ dan $600 \mathrm{~mm}$ pada 5 variasi perubahan frekuensi sinyal atau pulsa dengan memberikan arus DC. Jarak untuk pengujian $500 \mathrm{~mm}$ dan jarak $600 \mathrm{~mm}$, untuk travel length ballscrew yang terjauh pada penelitian ini adalah $600 \mathrm{~mm}$.

Digunakan 5 variasi perubahan sinyal atau pulsa tersebut meliputi: 800 puls/rev, 1600 puls/rev, 3200 puls/rev, 6400 puls/rev dan 12800 puls/rev, seperti pada Tabel 1.

Data Tabel 1 kemudian dibuat menjadi grafik. Dari Gambar 4 tersebut nantinya dapat diketahui linearitas pergerakan ballscrew, apabila persamaan linier pada grafik menghasilkan koefisien determinasi $\mathrm{R} 2=1$ atau mendekati maka linearitas gerakan yang dihasilkan dianggap sangat baik.

Data-data yang dihasilkan pada pengujian gerakan naik dengan beban pada arus DC setengah gelombang jarak $600 \mathrm{~mm}$ dan 500 $\mathrm{mm}$ ditarik rata-rata dan dibuat menjadi Tabel 2 dan grafik.

Tabel 1. Waktu Tempuh Gerak Naik tanpa Beban

\begin{tabular}{rcc}
\hline $\begin{array}{c}\text { Frekuensi sinyal } \\
\text { (puls/rev) }\end{array}$ & Jarak $\mathbf{6 0 0 ~} \mathbf{~ m m}$ & Jarak $\mathbf{5 0 0 ~} \mathbf{~ m m}$ \\
\hline 800 & 12.04 detik & 9.99 detik \\
1600 & 24.12 detik & 20.10 detik \\
3200 & 48.28 detik & 40.16 detik \\
6400 & 96.46 detik & 80.27 detik \\
12800 & 192.64 detik & 160.55 dtk \\
\hline
\end{tabular}

Tabel 2. Waktu Tempuh Gerak Naik dengan Beban

\begin{tabular}{rcc}
\hline $\begin{array}{c}\text { Frekuensi sinyal } \\
\text { (puls/rev) }\end{array}$ & Jarak $600 \mathbf{~ m m}$ & Jarak $\mathbf{5 0 0 ~} \mathbf{~ m m}$ \\
\hline 800 & 12.04 detik & 10.32 detik \\
1600 & 24.09 detik & 20.57 detik \\
3200 & 48.26 detik & 40.38 detik \\
6400 & 96.45 detik & 80.78 detik \\
12800 & 192.52 detik & 160.64 dtk \\
\hline
\end{tabular}

Gambar 5 menghasilkan persamaan linier $\mathrm{y}=0.015 \mathrm{x}+0.0742$ untuk pergerakan pada jarak $600 \mathrm{~mm}$. Pada jarak tersebut koefisien determinasi yang didapat adalah $\mathrm{R} 2=1$ sehingga linearitas gerak naik dengan beban pada arus DC setengah gelombang untuk jarak $600 \mathrm{~mm}$ adalah sangat baik.

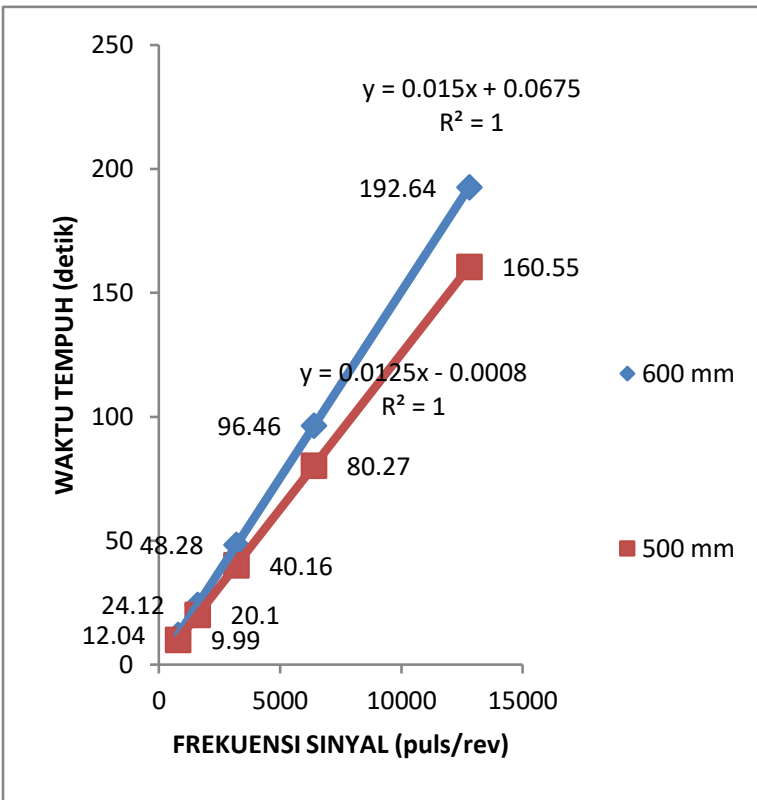

Gambar 4. Gerak Naik Tanpa Beban Arus DC Setengah Gelombang.
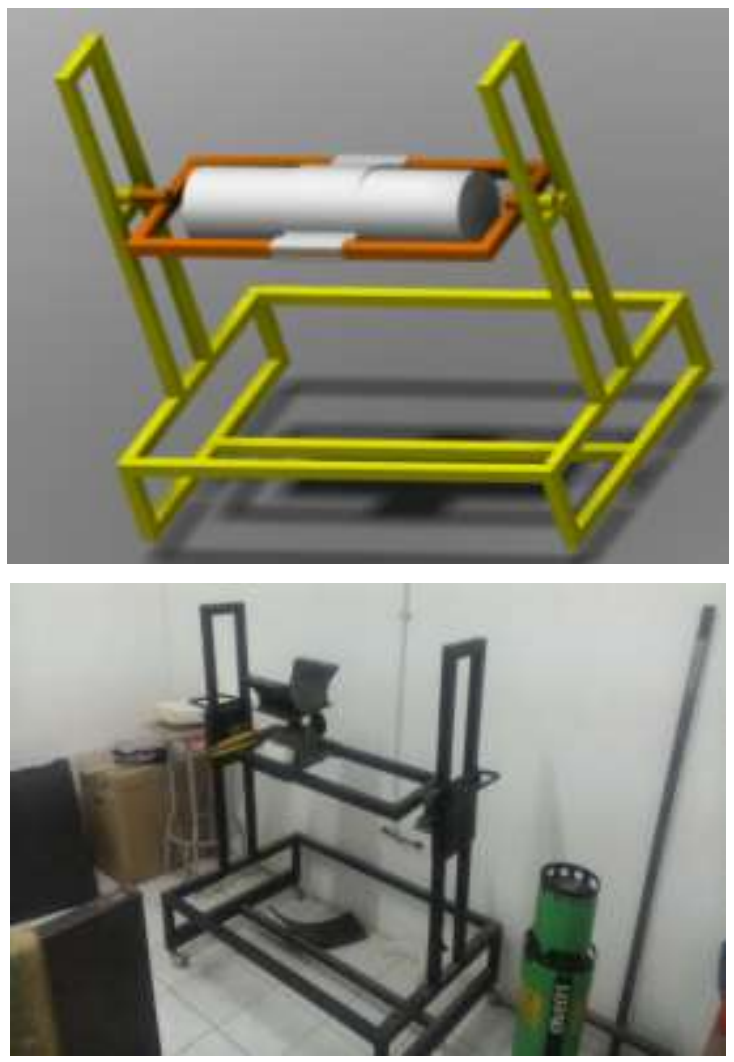

Gambar 5. Sistem Mekanik Pengatur Tabung Sinar-X Lorad LPX 200. 


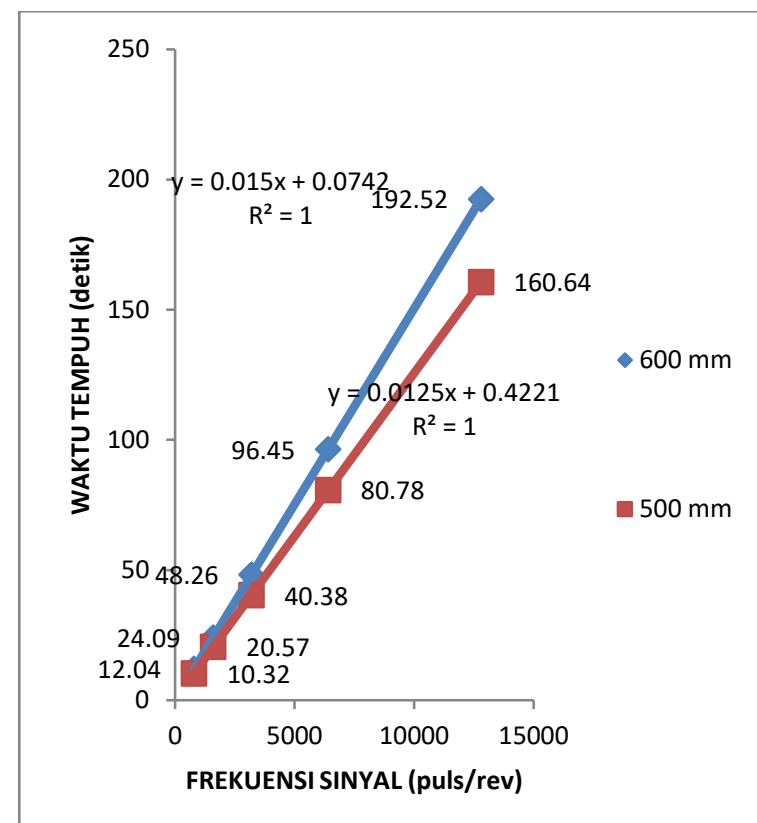

Gambar 5. Gerak Naik dengan Beban pada Arus DC Setengah Gelombang.

Tabel 3. Kecepatan Gerak Linier Naik dengan Beban Arus DC

\begin{tabular}{ccc}
\hline $\begin{array}{c}\text { Frekuensi } \\
\text { sinyal } \\
\text { (puls/rev) }\end{array}$ & Jarak $600 \mathrm{~mm}$ & Jarak $\mathbf{5 0 0 ~} \mathbf{~ m m}$ \\
\hline 800 & $49,83 \mathrm{~mm} /$ detik & $48,44 \mathrm{~mm} /$ detik \\
1600 & $24,90 \mathrm{~mm} /$ detik & $24,57 \mathrm{~mm} /$ detik \\
3200 & $12,43 \mathrm{~mm} /$ detik & $12,38 \mathrm{~mm} /$ detik \\
6400 & $6,22 \mathrm{~mm} /$ detik & $6,18 \mathrm{~mm} /$ detik \\
12800 & $3,12 \mathrm{~mm} /$ detik & $3,11 \mathrm{~mm} /$ detik \\
\hline
\end{tabular}

Tabel 4. Kecepatan Erak Linier Turun dengan Beban Arus DC

\begin{tabular}{ccc}
\hline $\begin{array}{c}\text { Frekuensi } \\
\text { sinyal } \\
\text { (puls/rev) }\end{array}$ & Jarak $\mathbf{6 0 0} \mathbf{~ m m}$ & Jarak $\mathbf{5 0 0 ~} \mathbf{~ m m}$ \\
\hline 800 & $50,20 \mathrm{~mm} /$ detik & $47,80 \mathrm{~mm} /$ detik \\
1600 & $24,88 \mathrm{~mm} /$ detik & $24,42 \mathrm{~mm} /$ detik \\
3200 & $12,42 \mathrm{~mm} /$ detik & $12,37 \mathrm{~mm} /$ detik \\
6400 & $6,21 \mathrm{~mm} /$ detik & $6,21 \mathrm{~mm} /$ detik \\
12800 & $3,15 \mathrm{~mm} /$ detik & $3,11 \mathrm{~mm} /$ detik \\
\hline
\end{tabular}

Untuk mencari kecepatan gerak linier yang nantinya akan digunakan dapat memanfaatkan data waktu tempuh yang ada (Tabel 3 dan Tabel 4). Pada Tabel 4 kecepatan gerak linier turun dengan beban arus DC gelombang penuh, kemudian pada beban turun dengan kecepatan gerak linier yang dihasilkan ditunjukkan pada Tabel 4.

Pada perancangan awal direncanakan kecepatan gerak linier yang akan digunakan adalah dengan memperhatikan aspek-aspek yang sudah disebutkan, menghasilkan kecepatan gerak linier untuk kinerja sistem mekanik (50 $\mathrm{mm} /$ detik) adalah dengan memberi motor penggerak frekuensi sinyal 800 puls/rev dengan jarak $600 \mathrm{~mm}$ dengan menggunakan arus DC setengah gelombang sebesar 5,7 ampere.

\section{KESIMPULAN}

Berdasarkan pengembangan yang telah dilakukan, dapat diambil beberapa kesimpulan sebagai berikut:

1. Alat yang dibuat sesuai perencanaan berupa sistem mekanik penggerak tabung sinar-X Lorad LPX 200 dengan mekanik roda gigi mampu digunakan untuk menggerakan beban berupa tabung sinar-X seberat $50 \mathrm{~kg}$ secara vertikal.

2. Hasil desain torsi motor untuk mengangkat tabung sinar-X sebesar 4,87 Nmm.

3. Gerakan yang dihasilkan oleh alat yang dibuat berjalan dengan linearitas sangat baik $(\mathrm{R} 2=1)$.

4. Kecepatan gerak linier yang paling mendekati $50 \mathrm{~mm} /$ detik didapat dengan memberi motor penggerak sinyal sebesar 800 puls/rev dengan arus dc setengah gelombang sebesar 5,7 A yang menghasilkan kecepatan 49,83 $\mathrm{mm} /$ detik ketika dinaikan dan 50,37 mm/detik ketika turun.

\section{DAFTAR PUSTAKA}

1. Toto Trikasjono, Djoko Marjanto, Agung Nugroho, 2007, "Perancangan Ruang Pengujian Kebocoran Pesawat Sinar-X Rigaku 250 KV Di STTN BATAN Yogyakarta", Seminar Nasional III SDM Teknologi Nuklir, Yogyakarta.

2. Suparno, Baskan Hanurajie, Teknik Radiografi: UTR (NDT) SERI A, Pusdiklat BATAN, 2008

3. Suparno, Anda, Sutrasno, "Konversi Paparan pada Perubahan kV Pesawat Sinar-X Rigaku-RF-250EGM, Widyanuklida Vol. 8 No. I-2, 2007

4. Robert L. Mott, Machine Elements in Mechanical Design, Prentice Hall, 2004.

5. LPX-200 Industrial, Imaging System Operator's Manual, New York,2013

6. Khurmi RS, Gupta JK, A Text Book Of Machine Design, Eurasia Publishing House LTD, New Delhi, 2005 
7. Asril, dan Abbas B., Konstruksi Perhitungan Pemakaian Bagian-Bagian Pesawat Sederhana. H. Stam : Jakarta,1952

8. Sularso, Dasar Perencanaan dan Pemilihan Elemen Mesin, Pradnya Paramita, Jakarta, 1997

9. Puji Hartono, Muhammad Naufal Fauzi, "Pengendalian Otomasi 3 Axis Berbasis PLC Pada Simulasi Proses Las", Metal Indonesia Vol. 36 No.1 , 2014

10. HIWIN, HIWIN Ballscrew \& Lead Screw Technical Information, Minsk: Belarussia, 2014. 